\title{
Interactive comment on "Comparison of aerosol LIDAR retrieval methods for boundary layer height detection using ceilometer backscatter data" by Vanessa Caicedo et al.
}

\begin{abstract}
Vanessa Caicedo et al.
caicedo.vanessa@gmail.com

Received and published: 10 January 2017

We appreciate the interest in our manuscript and for referring us toward this recent publication about the calculation of uncertainties from signals such as those of radiosonde and ceilometer measurements. We will include Biavati et al (2015) in the revised manuscript as a general reference to sensor related uncertainties. However, we feel that the uncertainties calculated by the presented method will not provide us with further information for the purpose of our study to arrive at the most reliable method for boundary layer height retrievals using aerosol backscatter data.
\end{abstract}

Interactive comment on Atmos. Meas. Tech. Discuss., doi:10.5194/amt-2016-340, 2016. 